of Fabry-Perot interference filters. In connexion with aluminium, the physical conditions during evaporation are considered with respect to the form of the deposited film. Evaporated coatings on plastic materials and the deposition on lacquered components also receive comment, along with the highly important shadow-casting and surface-replication procedures.

The section on cathodic sputtering is concisely written. The really salient features have been competently selected from the formidable amount of literature already existing 'on this phenomenon. Here again there is much of practical importance, though tempered with some theory.

The final part is very appropriate in view of the recent developments in optics involving the replace. ment of light-absorbing semi-transparent metal films with thin films of metal oxides, and the innovation of semi-conducting metal oxide films with high transparency as heating elements on glass. Also included are the preparation and properties of a variety of oxide films.

An extremely useful appendix lists the deposition characteristics and refractive indices of a range of inorganic compounds relevant to thin film formation by evaporation or sputtering schedules. The text is liberally provided with diagrams and references and contains a separate author-and subject-index. This is especially valuable in a work which will doubtless find its major value as a source of reference for many years to come. Twenty-four pages of plates complete the book. They are beautifully produced and serve as an admirable conclusion.

A. H. JARRETT

\section{THE HUMAN LYMPHATIC SYSTEM}

Lymphatics, Lymph and Lymphoid Tissue

By Prof. Joseph Mendel Yoffey and Dr. Frederick Colin Courtice. Second edition. Pp. vii +510 . (London: Edward Arnold (Publishers), Ltd., 1956.) $60 s$. net.

THIS book gives a critical review of the history and development of our knowledge concerning lymphatics, lymph and lymphoid tissue. The advances made in this field since Ludwig and his pupils first collected lymph a little less than a century ago is truly remarkable.

The early chapters give a full account of the arrangement and organization of the lymphatic system. The most important chapters are those dealing with the formation of lymph, lymph flow and lymph pressure. The controversy about the precise relationship between lymph and the interstitial fluid from which it arises is discussed in some detail. The authors give their own views on these problems and state that the main purpose of the lymphatics is to return to the blood stream the large protein molecules which pass from the blood capillaries into the tissue spaces. A comprehensive survey of the architecture of the capillary bed, the exchange of proteins through the capillary membrane and capillary pressure is given, and the differences between the blood capillary membrane and the membrane of the lymphatics are discussed. The authors conclude that, "The difference between the two membranes is that while one in offering resistance to the large protein molecules is affected by their osmotic force, the other in readily allowing the passage of such molecules is only affected by the gradient of hydrostatic pressure".

The final chapter gives some details of such disorders of function of the lymphatic system as circulating cedema, hunger codema, reaction to injury, lymphatic obstruction and lymphatics in the spread of infection. The book is not only a review of the work that has been done by others but also gives the conclusions reached by the authors as the result of their own investigations into the many aspects of the subject of lymphatics. An extensive and valuable bibliography is given at the end of each chapter.

The obvious conclusion to be drawn from reading the book is that it is an absolute necessity to all who are interested in the investigation of the lymphatic system.

W. J. Hamruton

\section{ZOOLOGY EXPANDS}

\section{The Zoological Record, Vol. 90}

Being the Records of Zoological Literature relating chiefly to the year 1953. Edited by G. Burder Stratton. Pp. 1750. (London : Zoological Society of London, 1956.) $120 s$.

$7 \mathrm{HE}$ present volume, relating mainly to zoological

literature published in 1953, shows an increase of three hundred pages on the previous year. Part of this increase is the result of including the sections on Vermes and Trilobita, which were omitted last year; but excluding this the over-all figures indicate a rise of approximately 10 per cent in the number of zoological publications between 1952 and 1953 . There is good evidence in support of the view that this growth of interest in zoology is continuing, for the sectional parts dealing with the literature for 1954 are larger than those for 1953, though the increment is not as great as was that of the previous year.

It should be emphasized that the sections of the "Zoological Record" are published separately as soon as they are ready for the press, in many cases more than a year before the bound volume is available. For example, the literature for 1954 is already available in sectional parts for most groups of the animal kingdom. Some groups present greater difficulties of recording than others, and the compilers of the various sections receive such slight remuneration that their work must be regarded as largely voluntary, so that the results are all the more commendable.

The difficulties of compiling a record of this kind with its lists of titles in all languages, apart from the classification of the information, can scarcely be over-estimated, and the editor and recorders of sections are to be congratulated on the issue of the majority of the sectional parts within two to three years of the publications to which they refer.

The sections give some indication of the activities in the various groups of the animal kingdom and, as usual, Insecta, with 4,024 titles, is by far the largest and comprises nearly one-third of the whole volume. Among the other sections, Aves still remains the most popular group, especially among the amateur zoologists, followed in descending order by Mammalia, Vermes, Protozoa, Mollusca, Pisces, Arachnida, Crustacea, Amphibia, Reptilia, Comprehensive Zoology, Echinoderma, Coelenterata, Brachiopoda, Trilobita (for 1952), Bryozoa, Protochordate and Porifera. Finally, there is a list of the new generic 